\title{
Safety concerns over biomedical waste management in a tertiary care centre of North Kerala
}

\author{
Rose Jacob S. ${ }^{1 *}$, Bhaskar A. ${ }^{2}$, Varkey George R. ${ }^{3}$, Harikrishnan G. ${ }^{4}$ \\ DOI: https://doi.org/10.17511/ijphr.2017.i1.04 \\ 1* Sabitha Rose Jacob, Assistant Professor, Department of Community Medicine, Government Medical College, Manjeri, Kerala, India. \\ ${ }^{2}$ Anitha Bhaskar, Associate Professor, Department of Community Medicine, Government Medical College, Manjeri, Kerala, India.
}

3 Rony Varkey George, Intern, Government Medical College, Manjeri, Kerala, India.

${ }^{4}$ Harikrishnan G, Intern, Government Medical College, Manjeri, Kerala, India.

Introduction: Exposure to infected body fluids and contact with contaminated materials while handling bio medical waste make health workers at high risk for blood borne infections. Objective: To assess safety precaution profile and biomedical waste management practices among different categories of health staff. Materials and methods: A cross sectional study was conducted among 141 health care personnel of a tertiary care center on single shift of a day using a structured pretested interview schedule. Data were analyzed using SPSS 16 trial version. Results: The study population included 25(17.6\%) doctors, 59(41.5\%) nurses, $14(9.9 \%)$ nursing assistants, $19(13.4 \%)$ hospital attendants and $13(9.2 \%)$ lab technicians and $11(7.8 \%)$ other daily wage cleaning staff involved in waste management. 104 (73.8\%)were females. 91(64.5\%)were permanent staff while 50 were on contract. 121(89.4\%) had work experience more than 1year.71(50.4\%)received no training on bio medical waste management and $18(12.8 \%) \mathrm{had}$ training within 6 months. Only 74(52.1\%) were fully immunized against Hepatitis B with a significantly less coverage among nursing assistants and hospital attendants $(p=.000)$. $60(42.6 \%)$ had sharp injury male sex $(p=.042)$, being in category of nursing assistants $(p=.000)$, permanent job status $(p=.000)$ and experience more than 5 years in absence of training $(p=.010)$ were risk factors significantly associated with sharp injury.101(72.3\%) always segregated waste as per categories and $110(78 \%)$ always used gloves while handling it. Conclusions: Around half of the health personnel are not following safety practices and sustained sharp injuries while handling biomedical waste. Only half of the health personnel were immunized against Hepatitis B.

Keywords: Biomedical waste, Hepatitis B immunization, Gloves, Masks, Training

Corresponding Author

Sabitha Rose Jacob, Assistant Professor, Department of Community Medicine, Government Medical College, Manjeri, Kerala, India. Email: sabitha1020@gmail.com
How to Cite this Article

Jacob SR, Bhaskar A, George RV, Harikrishnan G. Safety concerns over biomedical waste management in a tertiary care centre of North Kerala. Public Health Rev Int J Public Health Res. 2017;4(1):20-25. Available From https://publichealth.medresearch.in/index.php/ijphr/ article/view/56
To Browse

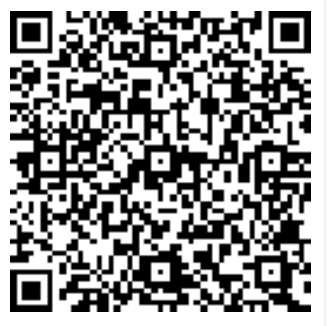

Manuscript Received 2017-02-28

Conflict of Interest No
Review Round 1 2017-03-10

Funding

Review Round 2
2017-03-18
Ethical Approval
Yes

Review Round 2

Yes
Review Round 3

Plagiarism X-checker $9 \%$
Accepted 2017-03-24

Note

() 2017 by Sabitha Rose Jacob, Anitha Bhaskar, Rony Varkey George, Harikrishnan G and Published by Siddharth Health Research and Social Welfare Society. This is an Open Access article licensed under a Creative Commons Attribution 4.0 international License https://creativecommons.org/licenses/by/4.0/ unported [CC BY 4.0]. 


\section{Introduction}

Biomedical waste is any waste generated during the process of diagnosis, treatment or immunization of human beings or animals or research activities and investigations [1]. It is a universal component of any hospital system. Unsafe handling of bio medical wastes poses a threat to those who deals with it and also for the environment. There is increased risk of transmission of blood borne infections like HBV, HCV and HIV for the handlers. Hence it is essential that due care is exercised while managing biomedical waste [2].

According to a WHO study, the annual estimated proportions of health-care workers exposed to blood-borne pathogens globally were $2.6 \%$ for $\mathrm{HCV}$, $5.9 \%$ for $\mathrm{HBV}$, and $0.5 \%$ for HIV, corresponding to about 16,000 HCV infections and 66,000 HBV infections in HCW worldwide [3]. Occupational exposures are responsible for about $40 \%$ of HBV infection in health care workers. The risk of acquiring HBV infection among this special population is about 10 times higher than in other groups [4].

In our country bio medical waste management guidelines were set very early. Bio medical waste management and handling rules of July 1998 (later amended in 2003 and 2011) is followed in most of the hospitals. Even after several years many hospitals in our country are yet to achieve the desired standards $[5,6]$ and according to Bio medical Waste management rules all health care workers handling bio medical waste should be immunized against Hepatitis B and Tetanus and biomedical waste should be handled without any adverse effect to human health and environment.

Handling, segregation, mutilation, disinfection, storage and transportation and final disposal are vital steps for the safe and scientific management of biomedical in any establishment [7]. Universal precautions are practices which prevent contact with potential blood and body fluids and it include use of Personal Protection Equipment, HBV vaccination, hand washing and disinfection and segregation of bio medical waste. Hepatitis $B$ vaccination is effective against infection. Protection has been estimated to persist for 25 years after primary vaccination schedule [8, 9-12]. Even though very effective, these practices are not universal. The level of awareness and practices differ among different categories of health personnel.
This study was conducted to find the current status of waste management practices in a tertiary care hospital and be enlightened on areas requiring improvement with specific objectives:

- To assess Hepatitis B vaccination status among different categories of health staff.

- To find out the proportion of health personnel sustained sharp injury, factors associated and extent to which safety measures are taken.

- To evaluate biomedical waste management at different stations by non-participatory observation.

\section{Materials and Methods}

Study design: Cross -sectional descriptive study

Study setting: A 500 bedded tertiary care centre of North Kerala

Study period from a period of July 2016 to August 2016.

Study population: All categories of health care staff working in the morning shift in various departments.

Sampling and sample size: Health care personnel of a tertiary care center on morning shift of a day were included in the study. Using convenient sampling 141 personnel were included in the study. Also 26 stations of the hospital dealing with any bio medical waste, were observed.

Data collection: Data on age, sex, qualification, work experience, type of employment, details of training, HBV vaccination status, history of sharp injury and usage of safety precautions were collected using an interview schedule. The different hospital sections dealing with bio medical waste were categorized to 26 stations and practices followed there and availability of facilities were observed by non-participatory method using a check list.

Statistical methods: Data were entered in excel sheet and analyzed using SPSS 16 trial version. General profile was described using proportions and differences in proportions were analyzed by chisquare test at significance level $p=0.05$.

Ethical consideration: The study was conducted after getting permission from hospital superintendent. Only the participants who gave informed consent were included in study. 


\section{Result}

A total of 141 health care personnel participated in the study. The study population included $25(17.6 \%)$ doctors , 59(41.5\%) nurses ,14(9.9\%) nursing assistants, 19 (13.4\%) hospital attendants and 13 (9.2\%)lab technicians and $11(7.8 \%)$ other workers directly involved in waste management consisting of 37 (26.2\%) males and 104 (73.8\%) females.

There were 136 (89.4\% )health personnel with work experience more than 1year, of these 34 (24.1\%) had 5-10 years of experience and 46 (32.6\%) had experience more than 10 years.

About half (50.4\%) of study population never attended a training program on bio medical waste management and 38 (27\%) had training before one year. Only $18(12.8 \%)$ received training within 6 months.

Among all categories of staff 50 (35.5\%) were working under contractual basis. Majority (90.9\%) of daily wage staff, directly handling bio medical wastes were contract workers and $61.5 \%$ of lab technicians too. This difference in type of employment among different categories was statistically significant $(p=0.00)$.

Only $74(52.1 \%)$ were fully immunized against Hepatitis B with a statistically significant low coverage among nursing assistants and hospital attendants $(p=.000)$.
Immunization status of different category of staff is shown in Table 1.

Table-1: Hepatitis B immunization status of different category of staff

\begin{tabular}{|l|l|l|l|}
\hline Category & \multicolumn{1}{|c|}{$\begin{array}{c}\text { Fully } \\
\text { immunized } \mathbf{N}= \\
\mathbf{7 4}(\%)\end{array}$} & $\begin{array}{c}\text { Partially } \\
\text { immunized } \mathbf{N}= \\
\mathbf{3 2}(\%)\end{array}$ & $\begin{array}{l}\text { Unimmunized/don't } \\
\text { know } \mathbf{N}=35(\%)\end{array}$ \\
\hline Doctors & $16(64)$ & $5(20)$ & $4(16)$ \\
\hline Nurses & $42(71.2)$ & $14(23.7)$ & $3(5)$ \\
\hline $\begin{array}{l}\text { Nursing } \\
\text { assistants }\end{array}$ & $6(42.8)$ & $3(21.4)$ & $5(35.8)$ \\
\hline Attenders & $1(5.3)$ & $2(10.52)$ & $16(84.2)$ \\
\hline $\begin{array}{l}\text { Lab } \\
\text { technician }\end{array}$ & $7(53.8)$ & $4(30.7)$ & $2(15.5)$ \\
\hline Others & $3(27.3)$ & $4(36.4)$ & $4(36.4)$ \\
\hline
\end{tabular}

There is statistically significant difference $(p=.000)$

Only one among 19 hospital attenders was fully immunized with 3 doses of Hepatitis $B$ vaccine. The remaining $4(10.52 \%)$ had taken 2 doses and $16(84 \%)$ of hospital attenders were either unimmunized or not sure of their status.

In our study population $60(42.6 \%)$ had sharp injury at least once during their work in a hospital .Main occurrence was among males, of them 21(56.8\%) had sharp injury. Profession wise $56 \%$ of doctors and $78.6 \%$ of nursing assistants had sharp injury in a life time. The determinants which showed significant difference among those who had sharp injury or no sharp injury is described in Table 2.

Table-2: History of sharp injury and Determinants

\begin{tabular}{|c|c|c|c|}
\hline Determinant & History of sharp Injury $n=60(\%)$ & No history of Sharp injury $n=81(\%) \backslash$ & $P$ value \\
\hline \multicolumn{4}{|l|}{ Sex } \\
\hline Male & $21(56.8)$ & $16(43.2)$ & $p=0.042$ \\
\hline Female & $39(37.5)$ & $65(63.5)$ & \\
\hline \multicolumn{4}{|l|}{ Profession } \\
\hline Doctors & $14(56)$ & $11(44)$ & $p=0.001$ \\
\hline Nurses Nursing assistants & $26(44.1)$ & $33(55.9)$ & \\
\hline Hospital attendants & $11(78.6)$ & $3(21.4)$ & \\
\hline Lab technicians & $7(36.8)$ & $12(63.2)$ & \\
\hline \multirow[t]{2}{*}{ Other daily wage staff } & $1(7.7)$ & $12(92.3)$ & \\
\hline & $1(9.1)$ & $10(91.9)$ & \\
\hline \multicolumn{4}{|l|}{ Job status } \\
\hline Permanent & $49(53.8)$ & $42(46.2)$ & $p=0.000$ \\
\hline Contract & $11(22)$ & $39(78)$ & \\
\hline \multicolumn{4}{|l|}{ HBV status } \\
\hline Fully vaccinated & $31(41.9)$ & $43(58.1)$ & $p>0.05$ \\
\hline Partially or unvaccinated & $30(44.1)$ & $38(55.9)$ & \\
\hline
\end{tabular}




\begin{tabular}{|c|c|c|c|}
\hline $\begin{array}{l}\text { Within } 5 \text { yrs } \\
\text { More than } 5 \text { yrs }\end{array}$ & $\begin{array}{l}38(40.4) \\
22(46.8)\end{array}$ & $\begin{array}{l}56(59.6) \\
25(53.2)\end{array}$ & $p>0.05$ \\
\hline \multicolumn{4}{|l|}{ Experience } \\
\hline Less than $1 \mathrm{yr}$ & $2(13.3)$ & $13(86.7)$ & $p=0.010$ \\
\hline $1-5$ yrs & $15(32.6)$ & $31(67.4)$ & \\
\hline $5-10$ yrs & $19(55.9)$ & $15(44.1)$ & \\
\hline More than $10 \mathrm{yrs}$ & $24(52.2)$ & $22(47.8)$ & \\
\hline
\end{tabular}

The factors found to be significantly associated with occurrence of sharp injury were male sex, permanent employment status, increasing experience, deficiency of training and being in the category of nursing assistants. A significant proportion $(56.8 \%)$ of males compared to females (37.5) had sharp injury.

Among all categories of staff a significantly high proportion of nursing assistants (78.6\%) reported sharp injury. More of permanent staff (53.8\%) reported sharp injury compared to contract staff. Vaccination status was similar in both groups.

Considering work experience, $55.9 \%$ among those with 5-10 years of work experience and $52.2 \%$ among those with more than 10 years work experience reported injury with sharps. This difference was statistically significant $(p=0.010)$. Even though it had no statistical significance, $76.1 \%$ those with more than 10 year work experience and $92.9 \%$ of those in 1 st year of service reported a potential exposure during the previous one year.

The frequency of training was found to be decreasing over years of work experience in our study. $93.3 \%$ of persons with less than 1 year of work experience had some training on bio medical
Waste management while only $52.2 \%$ among those with work experience more than 10 years attended a training program $(p=0.010)$.

Among all categories 95(66.7\%) had training within $1 \mathrm{yr}$, while $50 \%$ of nursing assistants lacked training and $92.9 \%$ among them sustained hazardous exposure within last year. Males had higher risk for sharp injury by chi square test $(p=.042)$ and by, univariate analysis $\mathrm{OR}=2.188(1.021,4.687)$ $\mathrm{p}=.002$ ).

Majority, $42(70 \%)$ neither reported the incident to higher authorities nor took any kind of post exposure prophylaxis. In the previous year 40 $(28.4 \%)$ had potential exposure namely sharp injury, blood splash. Eleven (7.8\%) had 5-10 such exposures and $6(4.3 \%)$ experienced it more than 10 times. And among them 26(43.3\%) were not protected against Hepatitis B.

Safety precautions: Safety precautions were assessed by the practice of using gloves while handling bio medical waste, use of needle cutter and categorization of bio medical waste. The responses to practices of biomedical waste management were different among different categories of staff which is discussed in Table 3.

Table-3: Safety precautions among different categories of health personnel

\begin{tabular}{|l|l|l|l|l|l|l|}
\hline \multirow{2}{*}{ Category } & \multicolumn{2}{|c|}{ Use of gloves } & \multicolumn{2}{c|}{ Category wise Waste segregation } & \multicolumn{2}{c|}{ Regular use of needle cutter } \\
\cline { 2 - 8 } & Always N (\%) & Sometimes to never N (\%) & Always N (\%) & Sometimes To never N (\%) & Always N (\%) & Sometimes To never N (\%) \\
\hline Doctors & $16(64)$ & $9(36)$ & $17(68)$ & $8(32)$ & $10(40)$ & $15(60)$ \\
\hline Nurses & $46(78)$ & $13(22)$ & $40(67.8)$ & $19(32.2)$ & $51(86.4)$ & $8(13.6)$ \\
\hline Nursing assistants & $9(64.3)$ & $5(35.7)$ & $13(92.9)$ & $1(7.1)$ & $12(85.7)$ & $2(14.3)$ \\
\hline Attenders & $18(94.7)$ & $1(5.3)$ & $17(89.8)$ & $2(10.2)$ & $13(68.4)$ & $6(31.6)$ \\
\hline Lab technician & $12(92.3)$ & $1(7.7)$ & $7(53.8)$ & $6(46.2)$ & $12(92.3$ & $1(7.7)$ \\
\hline others & $9(81.8)$ & $2(18.2)$ & $8(72.7)$ & $3(27.3)$ & $10(90.9$ & $1(9.1)$ \\
\hline & $\mathrm{p}=0.104$ & $\mathrm{p}=0.012$ & & $\mathrm{p}=0.000$ \\
\hline
\end{tabular}

Category wise waste segregation and placement in proper color coded bins were always followed by $102(72.3 \%)$. The work experience did not show any significant difference in their practice pattern while $83.3 \%$ of those who had training within six months
And followed color coded categorization. Other significant determinant was job status.70 (68.6\%) of permanent staff followed categorization guidelines compared to those on contractual appointment $(p=0.015)$. 
While handling bio medical waste 110 persons (78\%) always used gloves. Yet there was no provision for aprons, long rubber boots to be used during waste collection and segregation. A significantly low proportion of male staff (64.9\%) used gloves compared to female staff (82.7\%) $\mathrm{p}=0.024$. Among those who had training within 1 year $70 \%$ of always used gloves $(p=0.087)$.

For observation the hospital was divided into 26 stations. The availability of display boards for color coded segregation, provision of color coded buckets, availability of needle cutters and puncture proof containers for sharps and needles, practice of disinfection of sharps and any waste spillage on floor were observed using a checklist.

During our observation $60.7 \%$ stations had specific color coded charts. At other sites it was either not displayed or black and white in color. Colored waste buckets were available at $71.4 \%$ of stations. At $85.7 \%$ stations sharps were stored in puncture proof containers till disposal. At $75 \%$ stations waste segregation was done as per color categories.

Stations which lacked display charts also failed in correct segregation practice. All the stations had functioning needle cutters. Majority of stations (92.9\%) disinfected sharps items before disposal. Bio medical waste was seen spilled on the floor at $32.1 \%$ of observed stations.

\section{Discussion}

In our study $52 \%$ of study population were fully vaccinated against Hepatitis $B$ infection. This finding was similar to the observation from a tertiary care center in Delhi where $55.4 \%$ of study populations were vaccinated though the number of doses were unknown [13]. The vaccination coverage was significantly low among nursing assistants and attenders in our study.

The overall vaccination coverage was better in a United States based study where $81 \%$ coverage was observed among health staff. There too, a significant lower coverage was reported with nurse assistants and other patient care staff [14]. Full vaccination status among health care workers of Egypt was $15.8 \%$ with $3.5 \%$ coverage among cleaning staff [15].

One of the WHO study revealed that two thirds of hospitals among 22 countries were not following the proper infectious waste management practices.
Therefore, a continuous training on infectious waste was suggested for healthcare workers (HCWs) to control the menace of infectious diseases that can potentially endanger the patients, attendants, hospital staff, and residents in the neighborhood $[16,17]$.

Only $49.6 \%$ of our study population attended a training program on biomedical waste management. $72.3 \%$ hospital staff followed color coded waste categorization practices. By non- participatory observation it was revealed that $75 \%$ of observed stations practiced correct biomedical waste management guidelines.

Another study from a non-governmental tertiary center in same state observes that $70.7 \%$ were fully immunized against hepatitis B and $29.8 \%$ had received training on biomedical waste management [18]. We observed that recent training had a positive impact on bio medical waste management practices. There was difference in levels of KAP regarding bio medical waste management between trained and untrained personnel in a primary health care setting [19].

The occurrence of sharp injury was $41.8 \%$ in present study which is less compared Delhi based study where $79 \%$ had needle stick injury [20]. A qualitative study among tertiary care hospitals by Rakesh Kumar et al advised that a continuous and a comprehensive training of health personnel in various cadres could improve the infectious waste management practices in the hospitals [21].

\section{Conclusion and Recommendation}

Only half of the health personnel were immunized against Hepatitis B. All categories of staff are not getting regular training on waste management guidelines. A good proportion of sharp injuries sustained at work are not reported or followed up. There is no system for supervision of waste management at all.

Hepatitis B immunization and initial training on bio medical waste management should be given to all categories of staff before induction to the job. In service training should be given to all staff at definite intervals. The guidelines and its amendments should be updated timely to all levels of health care personnel. Hepatitis B vaccination must be made available free of cost to cleaning staff and those appointed on contract basis. 
There should be a system to report the occurrence of sharp injuries and arrange post exposure prophylaxis and further follow up of exposures.

\section{Reference}

01. Bio-medical Waste (Management and Handling) Rules, 1998. Ministry of Environment and Forests. Government of India. Available at: [Article] [Crossref]

02. Pruss A, Ciroult E, Rushbrook P. Safe Management of Wastes From Health-Care Activities. Geneva- WHO; Definition and Characterization of Health-Care Waste. 1999;20-27.

[Crossref]

03. Pruss-Ustun A, Rapiti E, Hutin Y. Sharps injuriesGlobal burden of disease from sharps injuries to health-care workers. Geneva- World Health Organization. 2003.

[Crossref]

04. Meireles LC, Marinho RT, Van Damme P. Three decades of hepatitis $B$ control with vaccination. World J Hepatol. 2015;Aug-28;7(18)2127-32. doi: 10.4254/wjh.v7.i18.2127 [Crossref]

05. Jhanvi G, Raju PV. Awareness and training need of biomedical waste management among undergraduate students, Andhra Preadesh. Indian J Public health. 2006;50(1)53-4.

[Crossref]

06. Rao P H. Hospital Management system-a case study of a South Indian city. Waste Manag Res. 2009; Jun-27(4)313-21.

doi: $\quad 10.1177 / 0734242 \times 09104128 \quad$ [Crossref]

07. Acharya D B, Singh Meeta. The Book of Hospital Waste Management. New Delhi, Minerva Press. 2000;15;47.

[Crossref]

08. Lin $\mathrm{HH}$, Wang $\mathrm{LY}, \mathrm{Hu} \mathrm{CT}$, Huang SC, Huang LC, Lin SS, et al. Decline of hepatitis $B$ carrier rate in vaccinated and unvaccinated subjects- six teen years after newborn vaccination program in Taiwan. J Med Virol. 2003;69(4)471-4. [Crossref]

09. Leuridan E, Van Damme P. Hepatitis B and the need for a booster dose. Clin Infect Dis. 2011;53(1)68-75.

doi: $10.1093 /$ cid/cir270 [Crossref]
10. Zanetti AR, Mariano A, Romanò L, D'Amelio R, Chironna M, Coppola RC. Long-term immunogenicity of hepatitis $B$ vaccination and policy for booster- an Italian multi centre study. Lancet. 2005;366(9494)1379-84.

[Crossref]

11. Liao SS, Li RC, Li H, Yang JY, Zeng XJ, Gong J, et al. Long-term efficacy of plasma-derived hepatitis B vaccine- a 15-year follow-up study among Chinese children. Vaccine. 1999; 17(2021)2661-6.

[Crossref]

12. Yuen MF, Lim WL, Chan AO, Wong DK, Sum SS, Lai CL. 18-year follow-up study of a prospective randomized trial of hepatitis $B$ vaccinations without booster doses in children. Clin Gastroenterol Hepatol. 2004;2(10)941-5. [Crossref]

13. Sukriti, Pati NT, Sethi A, Agrawal K, Agrawal K, Kumar GT, et al. Low levels of awareness, vaccine coverage, and the need for boosters among healthcare workers in tertiary care hospitals in India. J Gastroenterol Hepatol. 2008;23(11)1710-5.

doi: $10.1111 / \mathrm{j} .1440-1746.2008 .05483 . x$ [Crossref]

14. Simard EP, Miller JT, George PA, Wasley A, Alter $M J$, Bell $B P$, et al. Hepatitis $B$ vaccination coverage levels among healthcare workers in the United States, 2002-2003. Infect Control Hosp Epidemiol. 2007; Jul-28(7)783-90.

[Crossref]

15. Talaat M, Kandeel A, El-Shoubary W, Bodenschatz C, Khairy I, Oun S, et al. Occupational exposure to needlestick injuries and hepatitis $B$ vaccination coverage among health care workers in Egypt. Am J Infect Control. 2003; Dec-31(8)469-74.

[Crossref]

16. Rasheed S, Iqbal S, Baig LA, Mufti K. Hospital waste management in the teaching hospitals of Karachi. J Pak Med Assoc. 2005;55(5)192-5. [Crossref]

17. Ullah JH, Ahmed R, Malik JI, Khan MA. Outcome of 7-S, TQM technique for healthcare waste management. J Coll Physicians Surg Pak. $2011 ; 21(12) 731-4$.

doi: $12.2011 /$ JCPSP.731734 [Crossref] 
18. Ananthachari $K \mathrm{R}$, Divya CV. A study on assessment of knowledge on biomedical waste management among health care workers of Malabar Medical College Teaching Hospital, Calicut, Kerala, India. Int J Community Med Public Health. 2016 Sep;3(9)2409-13. doi: [Article] [Crossref]

19. Kumar R, Shaikh BT, Somrongthong R, Chapman RS. Practices and challenges of infectious waste management- A qualitative descriptive study from tertiary care hospitals in Pakistan. Pak J Med Sci. 2015 JulAug;31(4)795-798.

doi: $10.12669 / p j m s .314 .7988$ [Crossref]
20. Sarathy $P$, Surapaneni NN. A study on bio medical waste management and universal precautions among health care personnel working in a phc area. Int J Biol Med Res. 2013;4(1)2852-4.

[Crossref]

21. Rahul Sharma, SK Rasania, Anita Verma, Saudan Singh. Study of Prevalence and Response to Needle Stick Injuries among Health Care Workers in a Tertiary Care Hospital in Delhi, India. Indian J Community Med. 2010 Jan;35(1)74-77. doi: $10.4103 / 0970-0218.62565$ [Crossref] 